\title{
A NOTE ON NAME FORMS AND REFERENCES
}

$A_{\text {England will be aware, early English personal names can be modernized }}^{\text {s those who have read any amount of scholarship on Anglo-Saxon }}$ in a variety of fashions. The attempt here has been to conform to standard scholarly practice at present. Thus, the Old English vowel $æ$ (pronounced as a sharp 'a', rather like that in 'cat' or 'hat') is kept, but $\partial$ and $\mathrm{p}$ are replaced by their modern equivalent 'th' and $p$ by ' $w$ '. The attempt has otherwise been to keep as close as possible to the original (thus, Æthelstan not Athelstan, Eadwig not Edwy, etc.); however, where there are good modern equivalents of the name in question, these have been preferred (e.g. Alfred not Ælfred, Edgar not Eadgar). With non-English names the approach has been less systematic and more impressionistic. Here I generally follow the forms used in the Wiley Blackwell Encyclopedia of Anglo-Saxon England (Swein rather than Swegen or Sveinn, Olaf rather than Olav or Oláfr); otherwise, I seek to render them in the form best known to Anglophone students and scholars. Doubtless many inconsistencies remain, but hopefully it will be clear enough who is intended. When rulers are first mentioned in the main text, their reigns are given in parentheses; likewise, the episcopates and abbacies of important prelates are often given when they are first encountered.

My approach to referencing has been similarly pragmatic: I have attempted to cite all the most recent and relevant secondary literature, without seeking to be exhaustive. In order to avoid overburdening an 
already long text, articles are cited from their most recent place of appearance (or at least the most recent one known to me), except when this is in a rare or hard-to-find volume. Likewise, citations of sources are to the most recent edition; guidance on other editions and translations (if available) can generally be found there. Readers wishing to delve more fully into the sources of the period are pointed in the first instance towards Dorothy Whitelock's invaluable English Historical Documents. When sources are first mentioned, their date of composition is given (if known). For these purposes I follow standard scholarly convention in using ' $x$ ' to designate an unknown point during a span and '-' to designate the span itself: $997 \times 1002$ thus means 'written/completed at some point between 997 and 1002', whereas 997-1002 would mean 'written continuously between 997 and 1002'. 